\title{
Can ACE2 Receptor Polymorphism Predict Species Susceptibility to SARS-CoV-2?
}

\section{OPEN ACCESS}

Edited by:

Constantinos Tsioutis,

European University Cyprus, Cyprus

Reviewed by:

Ana Afonso,

University of São Paulo, Brazil Leiliang Zhang,

Shandong First Medical

University, China

*Correspondence:

Christian A. Devaux

christian.devaux@

mediterranee-infection.com

tPresent address:

Christian A. Devaux,

IHU-Méditerranée Infection, Marseille,

France

Specialty section:

This article was submitted to

Infectious Diseases - Surveillance,

Prevention and Treatment,

a section of the journal

Frontiers in Public Health

Received: 22 September 2020

Accepted: 23 November 2020

Published: 10 February 2021

Citation:

Devaux CA, Pinault L, Osman 10 and Raoult D (2021) Can ACE2 Receptor

Polymorphism Predict Species

Susceptibility to SARS-CoV-2?

Front. Public Health 8:608765.

doi: 10.3389/fpubh.2020.608765

\author{
Christian A. Devaux ${ }^{1,2 \star t}$, Lucile Pinault ${ }^{1}$, Ikram Omar Osman ${ }^{1}$ and Didier Raoult ${ }^{1,3}$ \\ ${ }^{1}$ Aix-Marseille Université, IRD, APHM, MEPHI, IHU-Méditerranée Infection, Marseille, France, ${ }^{2}$ CNRS, Marseille, France, \\ ${ }^{3}$ Fondation IHU-Méditerranée Infection, Marseille, France
}

A novel severe acute respiratory syndrome coronavirus, SARS-CoV-2, emerged in China in December 2019 and spread worldwide, causing more than 1.3 million deaths in 11 months. Similar to the human SARS-CoV, SARS-CoV-2 shares strong sequence homologies with a sarbecovirus circulating in Rhinolophus affinis bats. Because bats are expected to be able to transmit their coronaviruses to intermediate animal hosts that in turn are a source of viruses able to cross species barriers and infect humans (so-called spillover model), the identification of an intermediate animal reservoir was the subject of intense researches. It was claimed that a reptile (Ophiophagus hannah) was the intermediate host. This hypothesis was quickly ruled out and replaced by the pangolin (Manis javanica) hypothesis. Yet, pangolin was also recently exonerated from SARS-CoV-2 transmission to humans, leaving other animal species as presumed guilty. Guided by the spillover model, several laboratories investigated in silico the species polymorphism of the angiotensin I converting enzyme 2 (ACE2) to find the best fits with the SARS-CoV-2 spike receptor-binding site. Following the same strategy, we used multi-sequence alignment, 3-D structure analysis, and electrostatic potential surface generation of ACE2 variants to predict their binding capacity to SARS-CoV-2. We report evidence that such simple in silico investigation is a powerful tool to quickly screen which species are potentially susceptible to SARS-CoV-2. However, possible receptor binding does not necessarily lead to successful replication in host. Therefore, we also discuss here the limitations of these in silico approaches in our quest on the origins of COVID-19 pandemic.

Keywords: COVID-19, SARS-CoV-2, coronavirus, ACE2, in silico analyses

\section{INTRODUCTION}

The recent emergence of SARS-CoV-2, responsible for a respiratory disease named COVID-19 (Coronavirus Disease-2019), threatens public health (1-4). SARS-CoV-2 is responsible for respiratory infections, frequently asymptomatic but sometimes progresses to pneumonia, which, in its most severe forms can lead to death. SARS-CoV-2 is spreading very rapidly worldwide, and since WHO has declared COVID-19 as pandemic, about 54.5 million people have been infected worldwide (https://coronavirus.jhu.edu/map.html; 16 November, 2020). The case fatality rate of COVID-19 (estimated about 3.29\%) increases with age and the existence of underlying diseases $(2,3,5)$. Recently, Fang et al. (6) reported that the most distinctive comorbidities 
TABLE 1 | Viral tropism.

\begin{tabular}{llll}
\hline Receptor & Virus & Primary site of disease & Other organs \\
\hline ACE2 & SARS-CoV-1 & Lower respiratory tract & Multi-organ failure \\
& SARS-CoV-2 & Lower respiratory tract & Multi-organ failure \\
& HCoV-NL63 & Upper respiratory tract & - \\
DPP4/CD26 & MERS-CoV & Lower respiratory tract & Myocarditis, renal failure \\
CD13 & HCoV-229E & Upper respiratory tract & Gastrointestinal \\
HLA Class I & HCoV-OC43 & Upper respiratory tract & Gastrointestinal \\
& HCoV-HKU1 & Upper respiratory tract & Gastrointestinal \\
\hline
\end{tabular}

in patients who died from COVID-19 are hypertension, coronary heart diseases, cerebrovascular diseases, and diabetes. Soon after the characterization of SARS-CoV-2, it was demonstrated that this virus uses the angiotensin I converting enzyme 2 (ACE2) expressed on pneumocytes to enter human cells $(7,8)$. Several recently published papers reported the SARS-CoV-2 entry into target cells through interactions with ACE2 and serine protease TMPRSS2 priming, as well as the three-dimensional (3-D) structures involved in the interactions between the viral spike (S) protein and ACE2 (9-13). The polymorphism of ACE2 in human populations was recently documented, suggesting that these allelic differences could translate into differences in susceptibility to SARS-CoV-2 infection $(14,15)$. Insofar as the physiological function of ACE2 is to cleave angiotensin II into angiotensin (1-7), SARS-CoV-2 infection could cause a dysregulation of this peptidase leading to risk of malfunction of the ReninAngiotensin-Aldosterone pathway (16).

SARS-CoV-2 is the 7 th human coronavirus $(\mathrm{HCoV})$ reported to date. Previously, the first $\mathrm{HCoVs}$ described back in the 1960s were the HCoV-229E (Alphacoronavirus) and HCoVOC43 (Betacoronavirus lineage 2a), two agents of common winter cold. In 2003, the coronaviruses gained in notoriety with the emergence in Asia of SARS-CoV (Betacoronavirus lineage 2b), proven responsible for a severe acute respiratory syndrome (SARS) in humans with a case fatality rate of $9.6 \%$ (17). Within the next couple of years, the HCoV-NL63 (Alphacoronavirus lineage $1 \mathrm{~b}$ ) and HCoV-HKU1 (Betacoronavirus lineage 2a) were discovered. The HCoV-HKU1 was discovered in Hong Kong. The case fatality rate of the four $\mathrm{HCoVs}$ responsible for common winter cold was estimated to be $0.5-1.5 \%$ (18-20). In contrast to SARS-CoV and HCoV-HKU1 that emerged in Southeast Asia suggesting that this region is probably a hotspot for coronavirus emergence, the Middle East Respiratory Syndrome (MERS), caused by the MERS-CoV (Betacoronavirus lineage 2c), was reported in Saudi Arabia in 2012. This epidemic was characterized by an extremely high case fatality rate of $34.7 \%$ (21). The last coronavirus known to infect humans, SARS-CoV-2 (Betacoronavirus lineage 2b/Sarbecovirus), emerged in China in 2019 and shows 79.5\% nucleotide identity with SARS-CoV (22). It is interesting to highlight that HCoV-NL63, SARS-CoV, and SARS-CoV-2 spike proteins bind ACE2, indicating that several members of the coronavirus family have developed a preferential tropism for this receptor to enter target cells $[(23,24)$; Table 1$]$.
As soon as this new SARS-CoV-2 was discovered, many studies were initiated to understand the viral infection mechanisms and to clarify its origin. Consequently, the search for animal hosts was considered of high urgency for the control of COVID-19. The very first investigations focused on bats (order Chiroptera), which are considered a reservoir for coronaviruses $(\mathrm{CoV})$ and can be a source of epizootic and zoonosis (25-27). With 1,230 species, bats have the second highest number of species (after rodents) in the mammal world. They inhabit a multitude of ecological niches and carry a huge number of zoonotic viruses worldwide $(28,29)$. The probability for $\mathrm{CoV}$ to cross species barrier is higher in Southeast Asia where bats are sold in wildlife wet markets. Different species of Rhinolophus bats in China carry genetically diverse SARS-like coronaviruses, some of which are direct ancestors of SARS-CoV and SARS-CoV-2 $(30,31)$. Based on our knowledge of coronaviruses circulating in Chinese bats, it is not a surprise that SARS-CoV-2 was also considered to have originated from Rhinolophus bats. This turned out to be confirmed by elegant results showing that SARS-CoV-2 shares 96.2\% identity with the BatCoV RaTG13 strain from Rhinolophus affinis (22). Then, many laboratories started looking after an intermediate animal host. The snake (Ophiophagus hannah) and the pangolin (Manis javanica) were claimed to be intermediate hosts. The snake hypothesis was quickly ruled out (32). Although the pangolin hypothesis was the mainstream, it was also recently excluded $(33,34)$. At the same time, other species were singled out. To quickly study a large number of potential targets without having to grow virus on cells or infect animals with SARS-CoV-2, in silico approaches seemed to be a quite appropriate strategy since the three-dimensional structure of the S1 protein of SARS-CoV-2 was resolved, allowing the specification of the amino acids important for binding to ACE2 (9-13, 35). The knowledge previously accumulated on the interaction between ACE2 and the SAR-CoV spike was also of great value $(23,36,37)$. Interestingly, K353 and N90 in ACE2 are essential for infection likely due to their effect on the conformation of the $\alpha$-helix 1 of the receptor.

We revisited here the predicted binding properties between the viral S protein of SARS-CoV-2 and its ACE2 receptor, using in silico analysis based on alignment of receptor protein sequences from different species and structural modeling of ACE2 receptors. We found a good match between the in silico predictions of virus tropism and the species already considered to be possible intermediates between bats and humans for transmission of SARS-CoV-2. We report that positions K31 and Y41 in the $\alpha 1$ ridge, N82 and N90 in the loop, and $\alpha 3$ and $\mathrm{K} 353$ in loop and $\beta 5$ are those that must be examined in order to predict the possibility of a species to become infected by SARS-CoV-2. In agreement with previous reports suggesting that exchange N90T destroys a major N-glycosylation site in ACE2 (9, 10, 38), we confirm that N90 is likely a critical position in ACE2 for SARS-CoV-2 binding. The analysis of electrostatic potential surface generation of ACE2 variants highlight minor differences in surface charges for mouse and frog sequence insertions compatible with lower susceptibility of these species to SARS-CoV-2. Finally, the broad spectrum of potentially susceptible species argues in favor of 
the circulation model (33) rather than in favor of the spillover model (39).

\section{MATERIALS AND METHODS}

\section{ACE2 Protein Sequence}

ACE2 protein sequences from the NCBI reference sequence database: Rousettus leschenaultii (GenBank: ADJ19219.1), Rousettus leschenaultii (GenBank: BAF50705.1), Rousettus aegyptiacus (NCBI Reference Sequence: XP_015974412.1), Pteropus alecto (NCBI Reference Sequence: XP_006911709.1), Pteropus vampyrus (NCBI Reference Sequence: XP_011361275.1), Phyllostomus discolor (NCBI Reference Sequence: XP_028378317.1), Desmodus rotundus (NCBI Reference Sequence: XP_024425698.1), Miniopterus natalensis (NCBI Reference Sequence: XP_016058453.1), Pipistrellus abramus (GenBank: ACT66266.1), Eptesicus fuscus (NCBI Reference Sequence: XP_008153150.1), Myotis davidii (NCBI Reference Sequence: XP_015426918.1), Myotis lucifugus (NCBI Reference Sequence: XP_023609438.1), Myotis brandtii (NCBI Reference Sequence: XP_014399780.1), Hipposideros armiger (NCBI Reference Sequence: XP_019522936.1), Rhinolophus ferrumequinum (GenBank: ADN93470.1), Rhinolophus pearsonii (GenBank: ABU54053.1), Rhinolophus sinicus (GenBank: AGZ48803.1), Rhinolophus pusillus (GenBank: ADN93477.1), Rhinolophus macrotis (GenBank: ADN93471.1), Homo sapiens (GenBank: BAB40370.1), Macaca mulatta (NCBI Reference Sequence: NP_001129168.1), Paguma larvata (GenBank: AAX63775.1), Felis catus (GenBank: AAX59005.1), Mustela putorius furo (NCBI Reference Sequence: NP_001297119.1), Sus scrofa domestic (GenBank: ASK12083.1), Sus scrofa (NCBI Reference Sequence: NP_001116542.1), Rhinolophus sinicus (GenBank: AGZ48803.1), Manis javanica (NCBI Reference Sequence: XP_017505752.1), Mus musculus (NCBI Reference Sequence: NP_081562.2), Rattus rattus (NCBI Reference Sequence: XP_032746145.1), Gallus gallus (GenBank: QEQ50331.1), Pelodiscus sinensis (NCBI Reference Sequence: XP_006122891.1), Xenopus tropicalis (NCBI Reference Sequence: XP_002938293.2), and Ophiophagus hannah (GenBank: ETE61880.1).

\section{Comparison of Sequences}

All ACE2 sequences were compared using the Clustal Omega multiple sequence alignment (EMBL-EBI bioinformatic tool; Copyright ( ) EMBL 2020) (https://www.ebi.ac.uk/Tools/msa/ clustalo/). The simple Unweighted Pair Group Method with Arithmetic Mean (UPGMA) algorithm of hierarchical clustering available under the Clustal Omega tool was used to produce rooted dendrogram (pairwise similarity matrix to construct a phylogenetic tree).

\section{3-D Analysis and Electrostatic Potential Surface Generation}

The 3-D structure of ACE2 was retrieved according to the published data [PDB: 6M1D; (11)]. Three amino acid segments (30-41, 82-93, and 353-358) from $R$. sinicus, $M$. musculus, and $X$. tropicalis ACE2 proteins were inserted into a human ACE2 backbone sequence to determine whether or not these substitutions may change the 3-D structure of ACE2. Protein modeling for these chimeric sequences was performed using the Phyre2 server (40). The PyMOL 1.8.0 software (https://sourceforge.net/projects/pymol/files/pymol/1. $8 /$ ) and the Adaptative Poisson-Boltzmann Solver (APBS) tools plugin (https://pymolwiki.org/index.php/APBS) were used to generate electrostatic potential surfaces of the human ACE2 and its modified chimeric versions. The red color indicates an excess of negative charges near the surface and the blue color arises from a positively charged surface.

\section{RESULTS}

\section{ACE2 Receptor Polymorphism Among Species}

Using multiple sequence alignment, we first compared the ACE2 sequences of 18 bat species. We found that the variant ACE2 proteins perfectly grouped in the dendrogram according to the subspecies of bats (Figure 1A). When we studied the multiple sequence alignments of ACE2 from bats and examined the regions predicted by crystallography to be the regions of contact with the S1 spike of the SARS-CoV-2 (Figure 1B), we observed significant differences between species. Rhinolophus bats appeared to be appropriate candidates for binding to SARSCoV-2-related viruses, yet a species polymorphism was observed among the Rhinolophus (i.e., $R$. sinicus with $\mathrm{K} 31, \mathrm{Y} 41 \mathrm{H}, \mathrm{N} 82$, N90, and K353 and R. ferrumequinum with K31D, Y41H, N82, N90, K353). The K31D variant may possibly alter the binding of the SARS-CoV-2 spike to the ACE2 from $R$. ferrumequinum. Unfortunately, the ACE2 sequence of $R$. affinis hosting the closest relative to SAR-CoV-2, BatCoV-RaTG13, was not available from the database. The ACE2 sequences from other bat species living in various ecosystem and with various geographic distribution, show increased amino acids substitutions at positions considered to be required for viral S1 spike binding (e.g., D. rotundus with $\mathrm{K} 31 \mathrm{~N}, \mathrm{Y} 41, \mathrm{~N} 82 \mathrm{~T}, \mathrm{~N} 90 \mathrm{D}$, and K353N). It is worth noting that the three Rousettus and two Pteropus ACE2 proteins analyzed in this study were characterized by K31, Y41, and N82T (Rousettus) or N82A (Pteropus), N90D, and K353. We also found that the three ACE2 proteins from Myotis bats were characterized by K31N, $\mathrm{Y} 41 \mathrm{H}, \mathrm{N} 82 \mathrm{~T}$, N90, and K353, suggesting that these species are unlikely to replicate SARS-CoV-2-like ancestor-related viruses.

\section{The Central Role Played by ACE2 for Interspecies Virus Spread}

Unraveling which cellular receptors are used by SARS-CoV-2 for entry should provide insights into viral transmission among species. Before SARS-CoV-2, SARS-like CoV was previously found to circulate in Chinese horseshoe bats and to spread through wild Himalayan palm-civet sold as food in Chinese wildlife markets from Guangdong (41-43). SARS-CoV was also identified in weasels and raccoons in Chinese wet markets (37, 41, 43). Regarding SARS-CoV-2, the question remains how it got to humans. The hypothesis of pangolin ( $M$. javanica) as an intermediate host for SARS-CoV-2 quickly became mainstream 


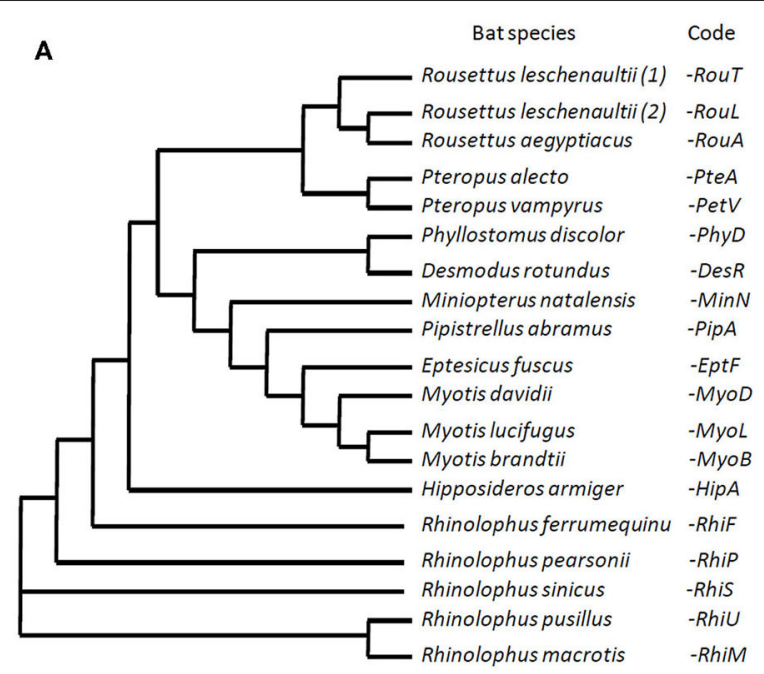

B

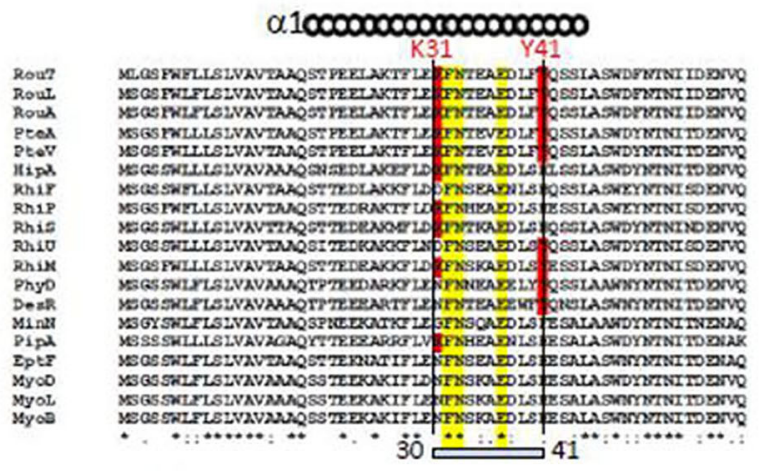

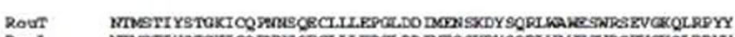

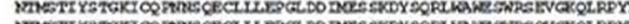

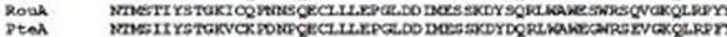

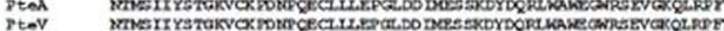

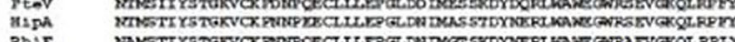

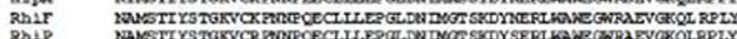

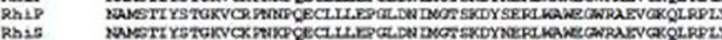

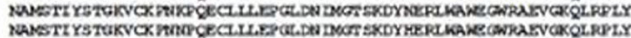

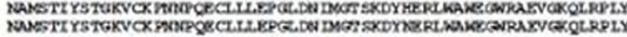

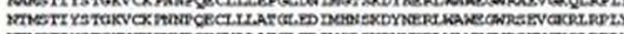

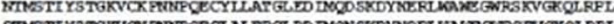

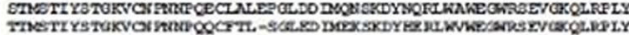

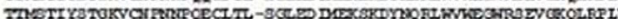

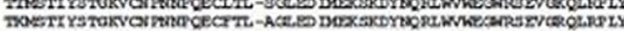

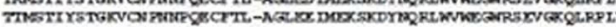

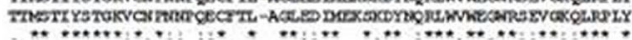

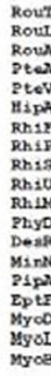

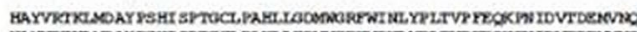

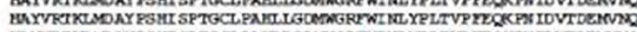

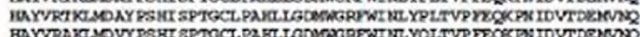

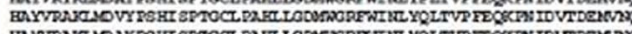

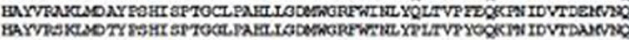

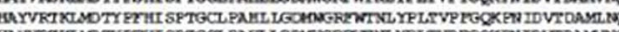

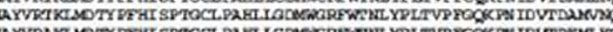
hl

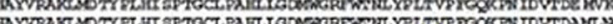
Arrot

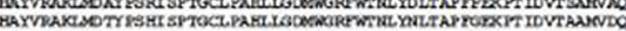

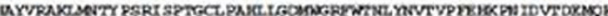

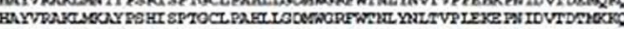

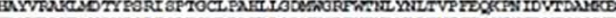
HAYVRAKCA

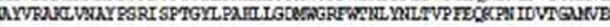

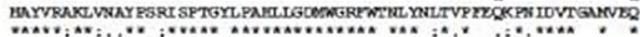

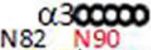

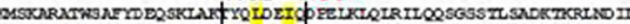

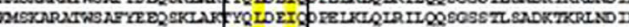

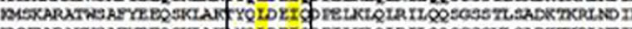

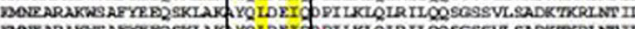

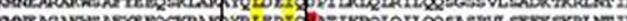

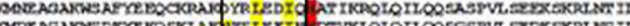

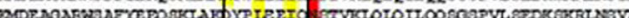

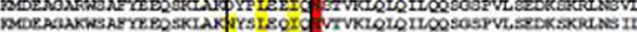

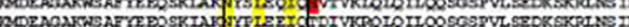

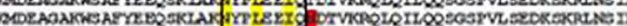

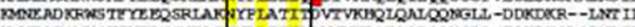

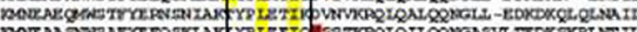

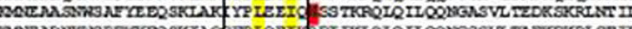

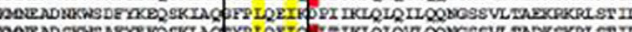

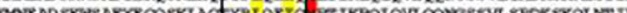

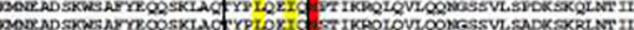

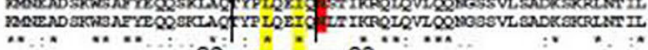

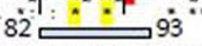

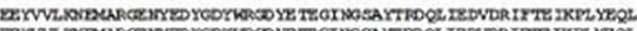

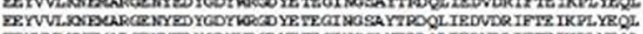

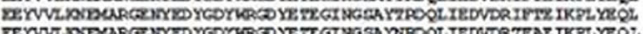

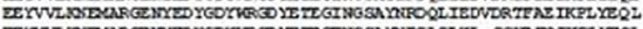

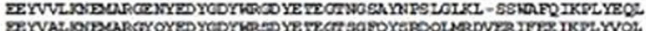

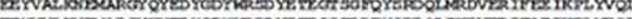

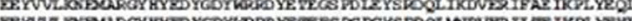
L FrVLLOA

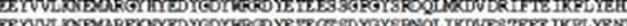

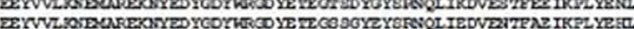

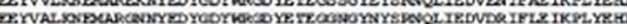

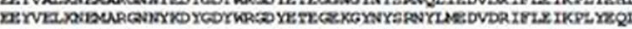

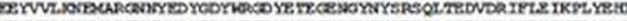
DETLL

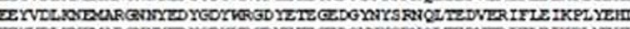
239
239

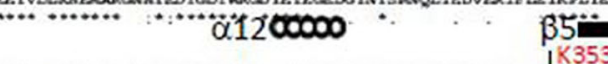

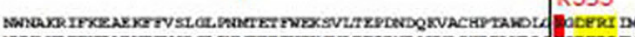

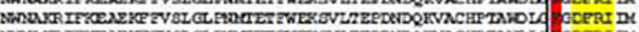

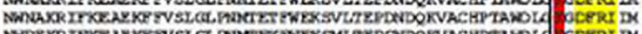

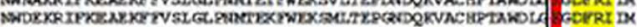

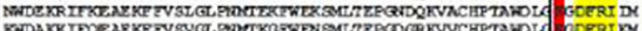

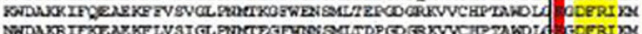

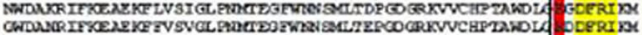

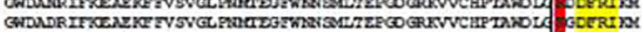

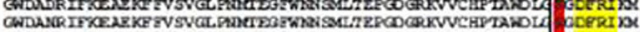

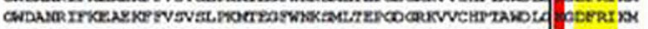

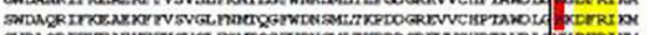

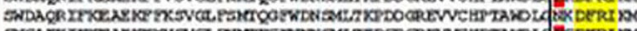

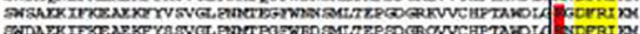

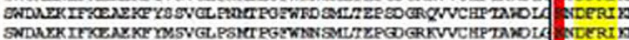

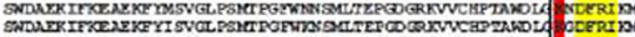

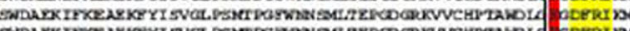

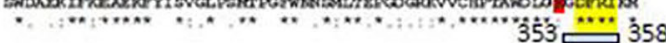

FIGURE 1 | Bat ACE2 sequence alignment. The ACE2 protein sequences from 18 species of bats were obtained from the NCBI reference sequence database: Rousettus leschenaultii, Rousettus aegyptiacus, Pteropus alecto, Pteropus vampyrus, Phyllostomus discolor, Desmodus rotundus, Miniopterus natalensis, Pipistrellus 
FIGURE 1 | abramus, Eptesicus fuscus, Myotis davidii, Myotis lucifugus, Myotis brandtii, Hipposideros armiger, Rhinolophus ferrumequinum, Rhinolophus pearsonii, Rhinolophus sinicus, Rhinolophus pusillus, and Rhinolophus macrotis. Clustal Omega multiple sequence alignment (EMBL-EBI bioinformatic tool; Copyright @ EMBL 2020) was used to compare the ACE2 protein sequences of these mammals considered at the origin of human coronaviruses. (A) Phylogenetic tree of bat ACE2 sequences built using the Clustal Omega multiple sequence alignment program and the UPGMA algorithm. The short code is used in (B). (B) Sequences alignment of bat ACE2 N-terminal (amino acids 1-360 of 805) protein sequences. Some of the amino acids important for viral tropism are in red (previous studies showed that residues 31 and 41 and regions $82-84$ and 353-357 are important for viral spike binding). Within the regions considered important for the interaction with the spike of SARS-CoV-2, the conserved amino acids are in yellow.

$(32,44)$. We recently demonstrated that pangolin is unlikely to be the intermediate host and that transmission to humans could just as easily have taken place via another animal (33).

We investigated the amino acid substitutions in 14 species of mammals, birds, reptiles, and amphibians, expected to be possible intermediate hosts for SARS-CoV-2 (Figure 2). Beside positions $\mathrm{K} 31, \mathrm{Y} 41$, and $\mathrm{K} 353$ reported in several studies to have been playing a major role for SARS-CoV-2 spike binding to ACE2, our multisequence alignment suggested that species carrying an N90 are more likely to be susceptible to SARSCoV-2 infection (it includes H. sapiens, M. mulatta, F. catus, $R$. sinicus, $M$. javanica, and $P$. sinensis) while others should be less susceptible to infection, except if the virus adapts to a second receptor for cellular binding and entry.

\section{Amino Acids K31, Y41, N90, and K353 in ACE2 Are Likely to Confer Susceptibility to SARS-CoV-2}

The analysis of 3-D structures of different ACE2 with respect to the amino acids found in regions 30-41, 82-93, and 353358 was studied after designing a backbone from the $H$. sapiens ACE2 in which the corresponding regions from $R$. sinicus, $M$. musculus, and $X$. tropicalis species were substituted to that from human. We found (Figure 3A) that these substitutions did not change the global 3-D structure of the molecule. However, when we analyzed the electrostatic potential surface of ACE2, more particularly in the regions 30-41, 82-93, and 353-358, we found that the substitution of those human ACE2 segments by the corresponding regions from $R$. sinicus, $M$. musculus, and $X$. tropicalis species slightly altered the electrostatic pattern of the molecule (Figure 3B). Indeed, in the region where amino acids Y41 and K353 are located in the human ACE2, when this region was substituted by sequences from mouse or frog origins, we observed a shift from neutral to basic electrostatic surface whereas the substitution for bat sequence did not change the electrostatic charge. The electrostatic surface was also different when the region containing $\mathrm{K} 31$ was substituted by that from bat or frog. These modifications are likely to be sufficient to reduce the interaction between SARS-CoV-2 spike and the variant ACE2.

\section{DISCUSSION}

Soon after the discovery of SARS-CoV-2, the cell surface exopeptidase ACE2 was found to serve as a viral receptor in human, and the first investigation of species susceptibility to this new virus demonstrated that SARS-CoV-2 is able to use Chinese horseshoe bat and swine but not mouse ACE2 to bind host cells (22). Since this pioneering work, several laboratories have intended to predict the utilizing capability by SARS-CoV-2 of ACE2 from different species using amino acid sequence comparisons aimed at identifying the possible intermediate hosts of SARS-CoV-2. This was made possible after published crystallographic analyses had determined which amino acids of ACE2 are essential for the attachment of the viral spike protein (9-11).

Our investigation suggests that SARS-CoV-like ancestral coronaviruses have adapted to the ACE2 receptor to replicate in bats. However, our analysis also suggests that probably not all bat species support SARS-CoV-like coronavirus ACE2 tropism. According to multisequence alignment, Rhinolophus bats appear to be appropriate candidates for ACE2 interaction with SARSCoV-2-related viruses, yet a species polymorphism in ACE2 sequences is observed among the Rhinolophus. $R$. sinicus with $\mathrm{K} 31, \mathrm{Y} 41 \mathrm{H}, \mathrm{N} 82$, N90, and K353 is a good candidate for SARSCoV-2-like virus capture whereas $R$. ferrumequinum with K31D, $\mathrm{Y} 41 \mathrm{H}, \mathrm{N} 82$, N90, and K353 can be predicted less susceptible to the virus binding. ACE2 sequences from other bat species show increased amino acid substitutions at positions considered required for viral spike binding (e.g., D. rotundus with $\mathrm{K} 31 \mathrm{~N}$, Y41, N82T, N90D, and K353N). In species expressing variant ACE2 not suitable for virus binding, another surface receptor could serve as viral entry into cells, but such viruses will be less likely to cross species barriers using an ACE2 protein as receptor in an intermediate host species. This can support the hypothesis of a long bat and virus co-evolution with bat species that replicate ACE2-tropic viruses like SARS-CoV and other species that replicate CD26-tropic viruses like MERS-CoV.

In order that a SARS-CoV-2-like virus can leave bats to infect another susceptible host, the infected bat must come into contact with an animal expressing an ACE2 receptor adapted to SARS-CoV-2-like virus binding. In agreement with other studies (44-46), our in silico search for host species able to pass the SARS-CoV-2 to humans supports the hypothesis that species bearing $\mathrm{K} 31$ and $\mathrm{K} 353$ amino acids are more likely to bind SARS-CoV-2. For example, ACE2 from M. javanica, M. putorius furo, and F. catus, considered SARS-CoV-2-susceptible species, show K31 and K353 amino acids whereas M. musculus, which is considered a SARS-CoV-2-resistant species, shows a $\mathrm{K} 31 \mathrm{~N}$ and $\mathrm{K} 353 \mathrm{H}$ variant. A Y41 also seems to be important, yet $R$. sinicus ACE2 expresses a $\mathrm{Y} 41 \mathrm{H}$ variant. It may account for the requirement of an intermediate host before being able to infect humans. A position not particularly stressed out in several SARS-CoV-2 studies that appear important is N90. Indeed, the 


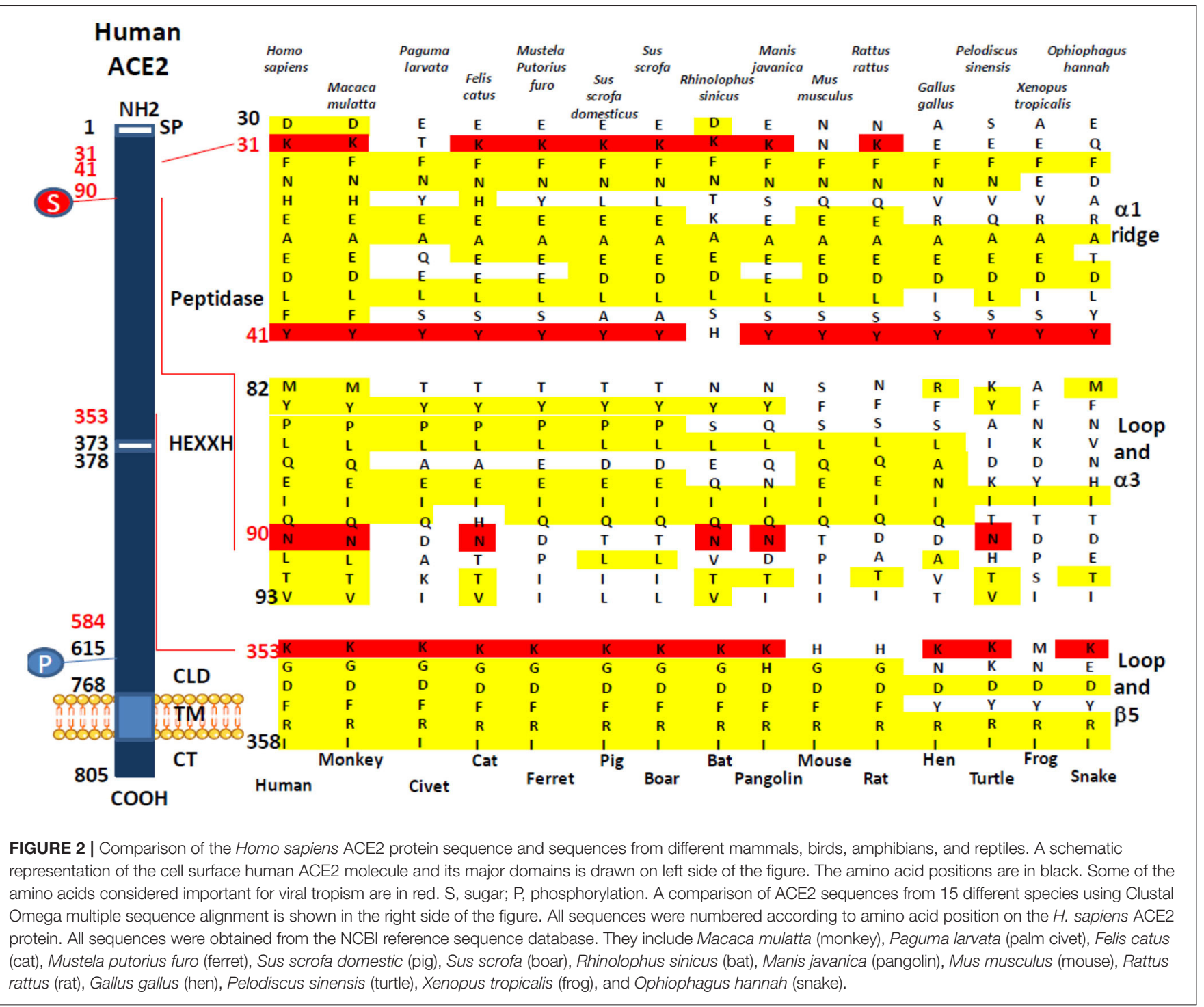

N90 that is found in $H$. sapiens final host and $R$. sinicus early host is also found in M. mulatta, M. javanica, $F$. catus, and $P$. sinensis, previously described susceptible to SARS-CoV-2 and possible intermediate hosts whereas N90D or N90T variants are found in the other species studied. This is also consistent with the earlier observation indicating that N90 was important for SARS-CoV and SARS-CoV-2 binding to $\operatorname{ACE} 2(9,10,23,38)$. This may explain why N90 may be very important for infection of host cells. Among the various in vitro antiviral activities of chloroquine described to date, it has been suggested that this molecule could prevent the glycosylation of ACE2 $(47,48)$. We could hypothesize that chloroquine blocks the N-glycosylation at position 90 of the ACE2 sequence, thereby preventing the attachment of SARS-CoV-2 spike to the receptor. However, what is surprising is the sequence of the P. larvata with K31T, Y41, N82T, N90D, and K353, since palm civet has been considered as the intermediate host for SARS-CoV and suggested to also serve as a possible intermediate host for SARS-CoV-2 (45), whereas with the absence of K31, in addition to N82 and N90 (which are expected to be glycosylated, thereby favoring interaction with the viral spike), palm civet appears to be an animal unlikely to be infected through ACE2. This discrepancy, also noticed by Wan et al. (35), should be further explored. Another surprising result is the absence of an N90 glycosylation site in the ACE2 from M. putorius furo since ferrets are now known to be susceptible to infection with SARS-CoV-2 (49-52). It would be interesting to study the affinity of the SARS-CoV-2 spike for the ferret ACE2. So far, the binding of SARS-CoV-2 to another viral entry receptor than ACE2 cannot be excluded. Very recently, it was reported that the enhanced human spreading of SARS-CoV2 compared to SARS-CoV could possibly be explained by the presence of a polybasic furin type cleavage site at the S1/S2 junction in the SARS-CoV-2 spike, which is not found in SARS$\mathrm{CoV}$ and that neuropilin-1 (NRP1) known to bind furin-cleaved substrates could be an entry cofactor that potentiates SARS-CoV2 infectivity (53). 


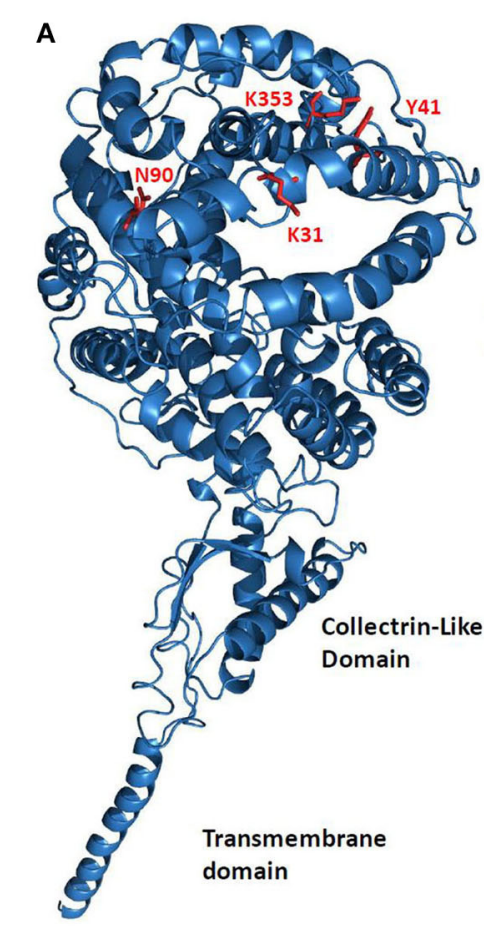

B
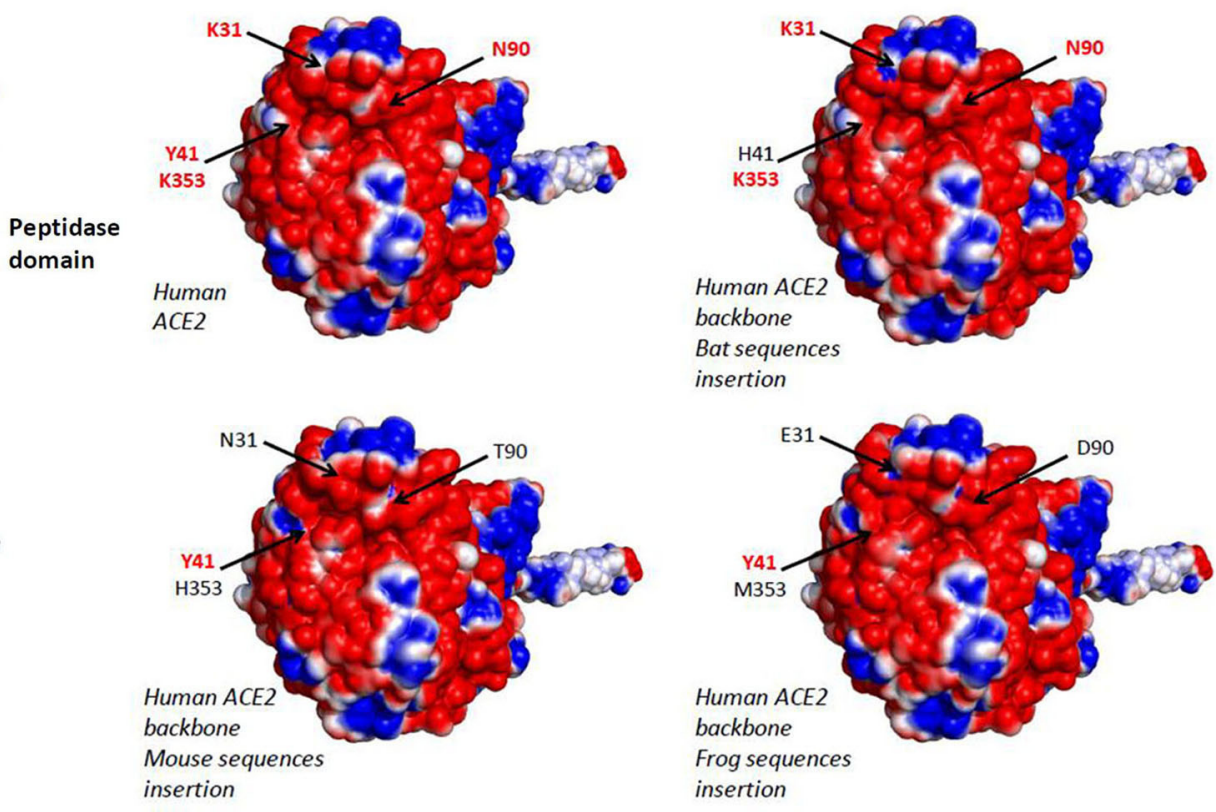

insertion

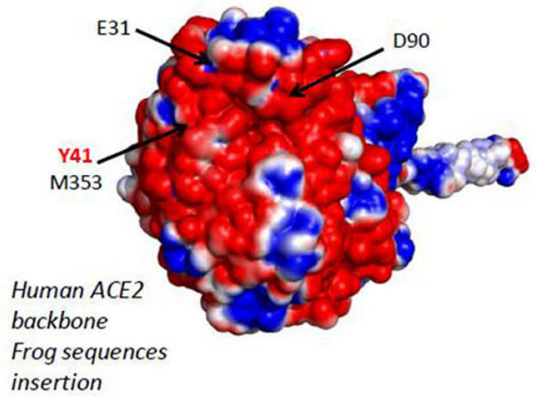

FIGURE 3 | 3-D model of ACE2. (A) Variant amino acids segments (30-41, 82-93, and 353-358) from Rhinolophus sinicus, Mus musculus, and Xenopus tropicalis species were superimposed on the Homo sapiens ACE2 3-D structure using the Phyre2 server. This model lacks the cytoplasmic tail of ACE2. (B) An electrostatic potential surface was generated using the PyMOL 1.8.0 software along with the APBS tool plugin. The upper left panel is a model of $H$. sapiens ACE2 extracellular region with its electrostatic potential distribution (red, acidic; white, neutral; blue, basic). The upper right and the two lower images represent simulation in which the $\alpha 1$ ridge, loop and $\alpha 3$, and loop and $\beta 5$ (see Figure 2, right panel) sequences from $R$. sinicus (bat), M. musculus (mouse), and X. tropicalis (frog) were substituted to the corresponding human sequences in a $H$. sapiens ACE2 backbone. The locations of amino acids $31,41,90$, and 353 are indicated by arrows.

Obviously, not all the species expressing an ACE2 predicted to bind SARS-CoV-2 are expected to be susceptible to infection by SARS-CoV-2. In silico studies focused on ACE2 protein polymorphism among species together with focused attention on amino acids expected to play a crucial role in the viral spike binding are suitable to predict ACE2 proteins susceptible to bind SARS-CoV-2 and can provide important clues regarding possible intermediate hosts or simply susceptible hosts. The ACE2 protein should contain amino acids essential for the viral spike binding and variants of ACE2 that lack such amino acids are not likely to allow virus binding. An impressive study combining phylogenetic analysis and critical site marking to predict the utilizing capability of ACE2 recently reported by Qiu et al. (46) compared the ACE2 sequences from 250 species with a specific focus on T20, K31, Y41, K68, Y83, S218, A246, K353, D355, R357, M383, P426, T593, N636, A714, R716, and A774 and concluded that SARS-CoV-2 might bind M. javanica (pangolin), F. catus (cat), Bos taurus (cow), Bubalus (buffalo), Capra hircus (goat), Ovis aries (sheep), and Columba livia (pigeon) ACE2 but not (M. musculus) murine ACE2. They also suggested to pay attention to Protobothrops mucrosquamatus (pallas pit viper), a common snake living in the Hubei Province of China. In their study, Luan et al. (45), investigated 42 mammalian ACE2 proteins from the wild animal protection list of Hubei Province. The authors focused on key amino acids K31, E35, D38, M82, and K353. According to their predictions, they considered that beside humans, the mammals whose ACE2 could bind to the S1 protein of SARSCoV-2 are bats (Rhinolophus macrotis, Rhinolophus sinicus, Rhinolophus pearsonii, Pteropus vampyrus, and Rousettus leschenaultii), pangolin (Manis javanica), palm civet (Paguma larvata), monkeys (Macaca mulatta, Pan troglodytes, Pongo abelii, Papio Anubis, and Callithrix jacchus), cat (Felis catus), dog (Canis lupus familiaris), ferret (Mustela putorius furo), and pig (Sus scrofa domesticus), among others (Rhinopithecus roxellana, Mustela erminea, Sus scrofa, Equus caballus, Bos taurus, Ovis aries, Oryctolagus cuniculus, Vulpes, Phodopus campbelli, Mesocricetus auratus, Heterocephalus glaber, Ictidomys tridecemlineatus, and Cricetulus griseus). The mammals whose ACE2 appeared unable to bind the $\mathrm{S} 1$ protein of SARS-CoV-2 included Rhinolophus ferrumequinum bats, rat (Rattus norvegicus), mouse (Mus musculus), camel (Camelus dromedarius), and others (Procyon lotor, Ornithorhynchus anatinus, Loxodonta africana, Erinaceus europaeus, Nyctereutes procyonoides, Suricata suricatta, Dipodomys ordii, and Cavia porcellus). They draw particular attention to the N82 amino acid in the ACE2 protein. Another study by Liu et al. (44), based on prediction of interactions between the S1 protein of SARS-CoV-2 and ACE2, that investigated monkey (Gorilla, Macaca), bat (Rhinolophus sinicus; Rhinolophus pearsonii), pangolin (Manis javanica), snake 
(Ophiophagus hannah), turtles (Chrysemys picta bellii, Chelonia mydas, and Pelodiscus. sinensis), and others (dog, cat, mouse), stressed a possible role as intermediate host animal reservoir for turtles. This study, which focused on positions T27, F28, D30, K31, H34, D38, Y41, Q42, M82, E329, K353, G354, D355, and R357, indicated that mouse and dog ACE2 showed multiple substitutions $(>5)$ among the 14 amino acids that retained their attention, an observation in agreement with the relative resistance of these species to infection by SARS-CoV-2. They suggested K31, Y41, and K353 to be key amino acids for viral spike binding. In recent weeks, several in silico studies aimed at finding an intermediate host have been published. Luan et al. (45) ruled out turtle and snake from the potential host list of SARS-CoV-2 and suggested that pangolin ACE2 was predicted to recognize SARS-CoV-2 less efficiently because it only preserved 14 of 20 critical amino acids they investigated, but found that primates, Bovidae, Cricetidae, and Cetacea (Neophocaena asiaeorientalis asiaeorientalis, found in the Yangtze River near Wuhan), are capable to recognize the RDB in S1 of SARS-CoV-2. A very elegant work by Damas et al. (54) scored 25 amino acids considered by this team as important for interaction between SARS-CoV-2 spike and ACE2 and they identified possible interaction for 252 mammal species, 72 birds, 65 fishes, 17 reptiles, and 4 amphibian ACE2 orthologs. It is worth noting that species scoring very low in Damas' study included the Chinese pangolin, Sunda pangolin, and white-bellied pangolin. Among Carnivora, 9/43 had the highest score including the domestic cat. Similar approaches that indicate a broad range of possible animal targets for SARS-CoV-2 are currently under evaluation for publication $(44,55)$. We can therefore also retain from these studies that, according to in silico analyses, numerous species are potentially susceptible to infection by SARS-CoV-2. This is a strong argument in favor of the virus circulation model in which there is not a single intermediate host but many susceptible species (33).

Although the in silico studies have the advantage of being easy to perform and to allow a quick investigation of the probability of SARS-CoV-2 infection for a large number of species, this strategy has its limits, and possible receptor binding does not necessarily mean successful replication in host. Once in the host, the virus should counteract the cell restriction factors and antiviral immune defense. Nothing can replace in vitro and in vivo experimentation. In vitro, SARS-CoV-2 was found to be able to infect and replicate on human Calu3 and Caco2 cell lines, VeroE6 and FRhK4 from non-human primate cell lines, LLCMK2 (monkey), RK-13 (Rabbit), PK-15 (pig), and CRFK (cat) cell lines (56). Interesting observations reported online (not peer reviewed) indicate that multiple ACE2 orthologs, human $(H$. sapiens), rhesus monkey (M. mulatta), dog (C. lupus familiaris), cat (F. catus), rabbit (O. cuniculus), and pangolin, can serve as receptors for SARS-CoV-2 when transiently expressed in 293T cells, whereas rat ( $R$. norvegicus) ACE2 does not (8).

Even when cells from a species are susceptible to SARS-CoV2 , this does not always translate into disease. Although it is more fastidious work than in silico and in vitro approach, evidence supporting that a species is susceptible to SARS-CoV-2 and can develop COVID-19-like symptoms can only be defined after in vivo infection. Interestingly golden Syrian hamster (M. auratus) and Chinese hamster (C. griseus) are known as animal models for SARS-CoV $(57,58)$. More recently, the golden Syrian hamster has been established as a model to study the transmission of SARSCoV-2 and the pathogenesis of COVID-19 (59, 60). Monkeys (M. mulatta, Macaca fascicularis, and Chlorocebus aethiops) were also found to be animal models for SARS-CoV with reports of pneumonitis in infected monkeys $(61,62)$. With SARS-CoV2, monkeys (M. mulatta and M. fascicularis) were found to be susceptible to the virus and develop mild disease COVID-19-like signs after infection $(63,64)$. Ferrets $(M$. putorius furo) were also used as an animal model for SARS-CoV and showed productive infection $(65,66)$. This species also was found to be susceptible to SARS-CoV-2 and develop mild disease COVID-19-like signs after infection $(49 ?-51)$. It was previously reported that young inbred mice supported SARS-CoV viral replication but failed to show clinical signs of disease $(67,68)$. Although mouse $(M$. musculus) ACE2 was considered unable to bind SARS-CoV-2 spike (35) and unable to support SARS-CoV-2 replication and disease development (69), it was reported that M. musculus transgenic for the human ACE2 gene are susceptible to infection by SARS-CoV-2 and develop mild disease COVID-19-like signs after viral exposure $(38,69)$. The paper recently published by Shi et al. (52) describes the investigation of the in vivo susceptibility of animals to replicate SARS-CoV-2. The authors reported that the virus replicated poorly in dogs, pigs, chickens, and ducks but efficiently infected ferrets and cats. In addition, these authors found that the virus can be transmitted from cat to cat through respiratory droplets. This result agrees with the report of experimental cat-to-cat transmission of SARS-CoV-2 (70) and human-to-cat transmission of SARS-CoV-2 (71). The accidental transmission of SARS-CoV-2 to tigers and lions at the Bronx Zoo (72) and minks (73) was also reported. Finally, Schlottau et al. (50) reported that pig and chickens were not susceptible to SARS-CoV-2 infection, whereas efficient virus replication was found in ferrets and fruit bats. The results obtained in our in silico study were compared with those of in vivo infection reported by different research teams (Table 2), and we observed a good match between the two experimental approaches.

Finally, if the absence of productive infection in animal models makes it possible to exclude certain species from the dynamics of transmission of SARS-CoV-2 to humans, the finding of productive infection provides little information on the origin of the human COVID-19 epidemic and pandemic. Human epidemic can only occur when there is a contact between human and an infected species, when this pathogen is compatible with human, and when human-to-human urban cycle is possible. The spillover model of virus transmission theorizes that the virus is developing into an epizootic stage in an animal population, reaching the threshold requirement for interspecies transmission (39). Thus, based on this model, identifying an animal reservoir appears to be essential to eradicate the disease by eliminating the infected animal host species. However, what we observe from the increasing number of reports aimed at identifying an animal reservoir is that numerous animal species are susceptible to SARS-CoV-2 and that no epizootics was reported with a SARS$\mathrm{CoV}$-2-like ancestral virus. This is the reason why it was recently 
TABLE 2 | Correlation between in silico ACE2 binding prediction and in vivo SARS-CoV-2 infection.

\begin{tabular}{|c|c|c|c|c|}
\hline Species & $\begin{array}{l}\text { Probability of SARS-CoV-2 } \\
\text { binding to ACE2 (in silico } \\
\text { prediction and score) }\end{array}$ & $\begin{array}{l}\text { In vivo SARS-CoV-2 replication (G clade } \\
\text { virus) }\end{array}$ & $\begin{array}{l}\text { Bibliographical } \\
\text { references for the in vivo } \\
\text { experimental infections }\end{array}$ & $\begin{array}{l}\text { Agreement between } \\
\text { in silico prediction and } \\
\text { in vivo data }\end{array}$ \\
\hline Human & Yes $(\text { Score } 5)^{\star}$ & COVID-19 outbreak & $(1-3)$ & Reference model \\
\hline Monkey & Yes (Score 5) & Susceptible (COVID-19-like signs) & $(63,64)$ & Yes \\
\hline Civet & No (Score 2) & Not tested & & Not applicable \\
\hline Cat & Yes (Score 4) & Susceptible to infection & $(52,70)$ & Yes \\
\hline Ferret & Yes (Score 3) & Susceptible (COVID-19-like signs) & $(49,50,52)$ & Yes \\
\hline Pig & Yes (Score 3) & Susceptible, yet the virus replicates poorly & $(50,52)$ & Yes \\
\hline Boar & Yes (Score 3) & Not tested & & Not applicable \\
\hline Bat & Yes (Score 3) & Susceptible to infection & $(50)$ & Yes \\
\hline Pangolin & Yes (Score 4) & Not tested & & Not applicable \\
\hline Mouse & No (Score 1) & $\begin{array}{l}\text { Resistant to infection (hACE2 humanized } \\
\text { mice are susceptible to infection and show } \\
\text { interstitial pneumonia) }\end{array}$ & $(38,69,74)$ & Yes \\
\hline Rat & No (Score 2) & Not tested & & Not applicable \\
\hline Hen & No (Score 2) & Not tested & & Not applicable \\
\hline Turtle & Yes (Score 3) & Not tested & & Not applicable \\
\hline Frog & No (Score 1) & Not tested & & Not applicable \\
\hline Snake & No (Score 2) & Not tested & & Not applicable \\
\hline
\end{tabular}

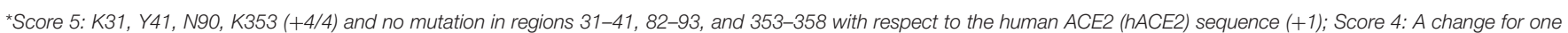

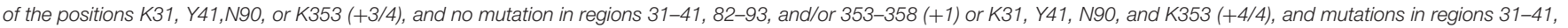

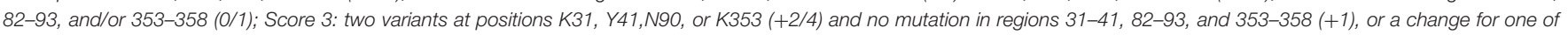

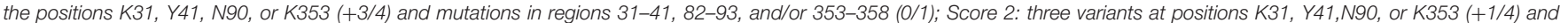

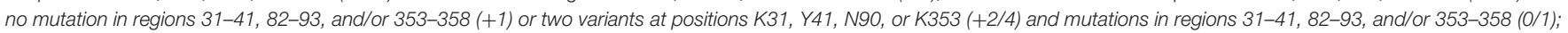

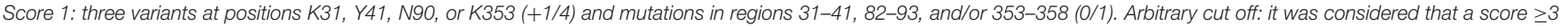
is predictive of attachment of the viral spike to ACE2 that can lead to infection.

suggested to consider a new model, the circulation model, which assumes that there is a broad circulation of virus in different species, and no requirement for zoonotic pressure or epizootic episode prior to the COVID-19 emergence in human (33). According to this new model, if the SARS-CoV-2-like ancestral virus can meet a host, if the virus spike RBD can bind ACE2 molecule even at low affinity, and if the target cells can be productively infected, then the adaptation to the host simply undergoes a quasispecies evolution process. So the scenario that can be suggested here is that the virus was circulating in many species, that following contact between one of these species and humans, a SARS-CoV-2-like virus came into contact with the ACE2 protein at the surface of human lung epithelial cells allowing infection to occur. ACE2 (100-kDa type I cell-surface glycoprotein of 805 amino acids) is expressed on both type I and type II alveolar epithelial lung cells as well as epithelial cells of oral mucosa, enterocytes of the small intestine, and arterial and venous endothelial cells contributing to the COVID19 disease $(38,75-78)$. Currently, SARS-CoV-2 is expected to undergo a quasispecies evolution process generating postinfection mutations under host-driven positive selection pressure $(32,79-83)$.

In conclusion, our results suggest that species carrying a sequence with $\mathrm{K} 31, \mathrm{Y} 41, \mathrm{~N} 90$, and $\mathrm{K} 353$ are likely to be susceptible to infection by SARS-CoV-2 (including $H$. sapiens, M. mulatta, F. catus, R. sinicus, M. javanica, and P. sinensis) while others should be less susceptible or resistant to infection, except if the virus adapts a second receptor for cellular binding and entry. The combination of 3-D structure analysis and electrostatic potential surface indicated that the substitution of human ACE2 regions 30-41, 82-93, and $353-358$ by the corresponding regions from $R$. sinicus, M. musculus, and $X$. tropicalis species did not significantly change the $3-\mathrm{D}$ structure of ACE2 but slightly modified the electrostatic potential surface of the molecule. These modifications are likely to be sufficient to alter the interaction of SARS-CoV-2 spike with the variants ACE2. The K31 and K353 in the $\alpha$-helical bundle of the ACE2 interface need to be accommodated in a largely hydrophobic environment to allow interaction with the viral spike RBD (9). The crystal structure analysis of ACE2 also suggested the presence of several hinge regions and N-glycosylations $(9,84)$, including the glycosylation of N90 considered essential for SARSCoV-2 binding. The ACE2 NxT/S consensus N-glycosylation motif $(54,85)$ is altered in 9 out of 19 bat species tested in this study (Figure 1). It is also absent on ACE2 from a number of species such as mouse or rat, which are considered resistant to infection, while it is present in species that have been shown to be susceptible to SARS-CoV-2 such as human, monkey, or cat (Figure 2). This highlights the in silico approach as a simple screening tool to identify species susceptible to SARS-CoV-2 in a given ecosystem $(74,86-88)$. SARS-CoV-2 infection was recently reported in mink farms and there is evidence that 
employees were infected with SARS-CoV-2 after minks became infected, suggesting that mink farms might become a reservoir for future spillover of SARS-CoV-2 to humans (73). We have aligned the mink ACE2 partial sequence available from GenBank (GenBank CCP86723.1) with the human ACE2 and observed that the mink ACE2 carries the K353 amino acid, but it was not possible to compare the other amino acids (K31, Y41, and N90) important for SARS-CoV-2 binding because the N-terminal part (1-318) of the protein is missing (data not shown). Facing the SARS-CoV-2 epidemic in minks, in the last few days, the Danish Government announced the culling of 17 million minks in rearing after researchers in Denmark have identified some 170 mutations (including a Y453F mutation in the viral spike) in samples from 40 mink farms and the report of mink-specific mutations of SARS-CoV-2 found in humans (89). The rationale behind this decision is the risk that these mutations might allow the virus to spread more easily among people, make it more deadly, and negatively impact the deployment of antiCOVID-19 vaccines. However, there is little evidence that these mutations are of particular concern; the real drivers of epidemics and pandemics are human activities, and trying to eradicate all supposed animal sources of infection is probably more fearful than rational (90).

\section{DATA AVAILABILITY STATEMENT}

The sequence data presented in this study can be found in the online ncbi database repositories. All sequences can

\section{REFERENCES}

1. Guan W, Ni ZY, Hu Y, Liang WH, Ou CQ, He JX, et al. Clinical Characteristics of Coronavirus Disease 2019 in China. New Engl J Med. (2020) 382:170820. doi: 10.1056/NEJMoa2002032

2. Zhu N, Zhang D, Wang W, Li X, Yang B, Song J, et al. A novel coronavirus from patients with Pneumonia in China, 2019. New Engl J Med. (2020) 382:727-33. doi: 10.1056/NEJMoa2001017

3. Huang C, Wang Y, Li X, Ren L, Zhao J, Hu Y, et al. Clinical features of patients infected with 2019 novel coronavirus in Wuhan, China. Lancet. (2020) 395:497-506. doi: 10.1016/S0140-6736(20)30183-5

4. Frutos R, Lopez-Roig M, Serra-Cobo J, Devaux CA. COVID-19: the conjunction of events leading to the coronavirus pandemic and lessons to learn for future threats. Front Med. (2020) 7:223. doi: 10.3389/fmed.2020.00223

5. Sun P, Lu X, Xu C, Sun W, Pan B. Understanding of COVID-19 based on current evidence. J Med Virol. (2020) 92:548-51. doi: 10.1002/jmv.25722

6. Fang L, Karakiulakis G, Roth M. Are patients with hypertension and diabetes mellitus at increased risk for COVID-19 infection? Lancet. (2020) 8:e21. doi: 10.1016/S2213-2600(20)30116-8

7. Zhuang MW, Cheng Y, Zhang J, Jiang XM, Wang L, Deng J, Wang $\mathrm{PH}$. Increasing Host Cellular Receptor-Angiotensin-Converting Enzyme 2 (ACE2) Expression by Coronavirus may Facilitate 2019-nCoV (or SARS-CoV2) Infection. J. Med. Virol. (2020) doi: 10.1002/jmv.26139. [Epub ahead of print].

8. Zhao Y, Zhao Z, Wang Y, Zhou Y, Ma Y, Zuo W. Single-cell RNA expression profiling of ACE2, the receptor of SARS-CoV-2. Am. J. Resp. Crit. Care Med. (2020) 202:756-9. doi: 10.1164/rccm.202001-0179LE

9. Shang J, Ye G, Shi K, Wan Y, Luo C, Aihara H, et al. Structural basis of receptor recognition by SARS-CoV-2. Nature. (2020) 581:2214. doi: 10.1038/s41586-020-2179-y by found at https://www.ncbi.nlm.nih.gov/genbank and the accession numbers are indicated in the Materials and Methods section.

\section{AUTHOR CONTRIBUTIONS}

CD performed the Clustal Omega analysis, designed the figures, and wrote the paper. LP performed the 3-D analysis. IO worked on the art design of figures. DR obtained the funding and supervised the study. All authors reviewed and approved the final version of the manuscript. All authors contributed to conceive the manuscript.

\section{FUNDING}

This work was supported by the French Government under the Investissements d'avenir (Investments for the Future) program managed by the Agence Nationale de la Recherche (ANR, fr: National Agency for Research) (reference: Méditerranée Infection 10-IAHU-03).

\section{ACKNOWLEDGMENTS}

We thank Jean-Marc Rolain, Bernard Davoust, and Aurélie Caputo for stimulating discussions. A previous version of this paper, not peer-reviewed, has been made available online on Research Square since 28 April 2020, Devaux et al. (86).
10. Lan J, Ge J, Yu J, Shan S, Zhou H, Fan S, et al. Structure of the SARS-CoV-2 spike receptor-binding domain bound to the ACE2 receptor. Nature. (2020) 581:215-20. doi: 10.1038/s41586-020-2180-5

11. Yan R, Zhang Y, Li Y, Xia L, Guo Y, Zhou Q, et al. Structural basis for the recognition of the SARS-CoV-2 by full-length human ACE2. Science. (2020) 367:1444-8. doi: 10.1126/science.abb2762

12. Hoffmann M, Kleine-Weber H, Schroeder S, Krüger N, Herrler T, Erichsen $\mathrm{S}$, et al. SARS-CoV-2 cell entry depends on ACE2 and TMPRSS2 and is blocked by a clinically proven protease inhibitor. Cell. (2020) 181:110. doi: 10.1016/j.cell.2020.02.052

13. Wrapp D, Wang N, Corbett KS, Goldsmith JA, Hsieh CL, Abiona O, et al. Cryo-EM structure of the 2019-nCoV spike in the prefusion conformation. Science. (2020) 367:1260-3. doi: 10.1126/science.abb2507

14. Luo Y, Liu C, Guan T, Li Y, Lai Y, Li F, et al. Association of ACE2 genetic polymorphisms with hypertension-related target organ damages in south Xinjiang. Hypertens Res. (2019) 42:681-9. doi: 10.1038/s41440-0180166-6

15. Cao Y, Li L, Feng Z, Wan S, Huang P, Sun X, et al. Comparative genetic analysis of the novel coronavirus (2019-nCoV/SARS-CoV2) receptor ACE2 in different populations. Cell Discov. (2020) 6:11. doi: 10.1038/s41421-020-0147-1

16. Devaux CA, Rolain JM, Raoult D. ACE2 receptor polymorphism: Susceptibility to SARS-CoV-2, hypertension, multi-organ failure, and COVID-19 disease. J Microb Immunol Infect. (2020) 53:425-35. doi: 10.1016/j.jmii.2020.04.015

17. Marra MA, Jones SJ, Astell CR, Holt RA, Brooks-Wilson A, Butterfield YSN, et al. The genome sequence of the SARS-associated coronavirus. Science. (2003) 300:1399-404. doi: 10.1126/science. 1085953

18. Kiyula PK, Agoti CN, Munywoki PK, Njeru R, Bett A, Otieno JR, et al. Human Coronavirus NL63 molecular epidemiology and evolutionary patterns in rural coastal Kenya. J Inf Dis. (2018) 217:1728-39. doi: 10.1093/infdis/jiy098 
19. Zhang SF, Tuo JL, Huang XB, Zhu X, Zhang D-M, Zhou K, et al. Epidemiology characteristics of human coronaviruses in patients with respiratory infection symptoms and phylogenetic analysis of HCoV-OC43 during 2010-2015 in Guangzhou. PLoS ONE. (2018) 13:e0191789. doi: 10.1371/journal.pone.0191789

20. Choi WI. Comparison of the clinical characteristics and mortality of adults infected with human coronaviruses $229 \mathrm{E}$ and OC43. Res Square. (2019). doi: 10.21203/rs.2.15496/v1

21. Zaki AM, van Boheemen S, Bestebroer TM, Osterhaus ADME, Fouchier RAM. Isolation of a novel coronavirus from a man with pneumonia in Saudi Arabia. New Engl J Med. (2012) 367:1814-20. doi: 10.1056/NEJMoa1211721

22. Zhou P, Yang X-L, Wang X-G, Hu B, Zhang L, Zhang W, et al. A pneumonia outbreak associated with a new coronavirus of probable bat origin. Nature. (2020) 579:270-3. doi: 10.1038/s41586-020-2012-7

23. Li W, Zhang C, Sui J, Kuhn JH, Moore MJ, Luo S, et al. Receptor and viral determinants of SARS-coronavirus adaptation to human ACE2. EMBO J. (2005) 24:1634-43. doi: 10.1038/sj.emboj.7600640

24. Glowacka I, Bertram S, Herzog P, Pfefferle S, Steffen I, Muench MO, et al. Differential downregulation of ACE2 by the spike proteins of severe acute respiratory syndrome coronavirus and human coronavirus NL63. J Virol. (2010) 84:1198-205. doi: 10.1128/JVI.01248-09

25. Saif LJ. Animal coronaviruses: what can they teach us about the severe acute respiratory syndrome? Rev Sci Tech. (2014) 23:64360.doi: 10.20506/rst.23.2.1513

26. Hu B, Ge X, Wang LF, Shi Z. Bat origin of human coronaviruses. Virology J. (2015) 12:221. doi: 10.1186/s12985-015-0422-1

27. Forni D, Cagliani R, Clerici M, Sironi M. Molecular evolution of human coronavirus genomes. Trend Microbiol. (2017) 25:3548. doi: 10.1016/j.tim.2016.09.001

28. Afelt A, Devaux CA, Serra-Cobo J, Frutos R. Bats, bat-borne viruses, and environmental changes. IntechOpen. (2018) Chapter 8, 113-31. doi: 10.5772/intechopen.74377

29. Wong ACP, Li X, Lau SKP, Woo PCY. Global epidemiology of bat coronaviruses. Viruses. (2019) 11:174. doi: 10.3390/v11020174

30. Ge XY, Li JL, Yang XL, Chmura AA, Zhu G, Epstein JH, et al. Isolation and characterization of a bat SARS-like coronavirus that uses the ACE2 receptor. Nature. (2013) 503:535-8. doi: 10.1038/nature12711

31. Afelt A, Frutos R, Devaux C. Bats, coronaviruses, and deforestation: toward the emergence of novel infectious diseases? Front Microbiol. (2018) 9:702. doi: $10.3389 /$ fmicb.2018.00702

32. Zhang C, Zheng W, Huang X, Bell EW, Zhou X, Zhang Y. Protein structure and sequence reanalysis of $219-\mathrm{nCoV}$ genome refutes snakes as its intermediate host and the unique similarity between its spike protein insertions and HIV-1. J Proteome Res. (2020) 19:1351-60. doi: 10.1021/acs.jproteome.0c00129

33. Frutos R, Serra-Cobo J, Chen T, Devaux CA. COVID-19: time to exonerate the pangolin from the transmission of SARS-CoV-2 to humans. Inf Genet Evol. (2020) 84:104493. doi: 10.1016/j.meegid.2020.104493

34. Liu P, Chen W, Chen J-P. Viral metagenomics revealed Sendai virus and coronavirus infection of Malayan pangolins (Manis javanica). Viruses. (2019) 11:979. doi: 10.3390/v111 10979

35. Wan Y, Shang J, Graham R, Baric RS, Li F. Receptor recognition by the novel coronavirus from Wuhan: an analysis based on decade-long structural studies of SARS coronavirus. J Virol. (2020) 94:e00127-20. doi: 10.1128/JVI.00127-20

36. Babcock GJ, Esshaki DJ, Thomas WDJr, Ambrosino DM. Amino acids 270 to 510 of the severe acute respiratory syndrome coronavirus spike protein are required for interaction with receptor. J Virol. (2004) 78:455260. doi: 10.1128/JVI.78.9.4552-4560.2004

37. Li W, Wong SK, Li F, Kuhn JH, Huang IC, Choe H, et al. Animal origins of the severe acute respiratory syndrome coronavirus: Insight from ACE2-S-protein interactions. J Virol. (2006) 80:4211-9. doi: 10.1128/JVI.80.9.4211-4219.2006

38. Sun J, He WT, Wang L, Lai A, Ji X, Zhai X, et al. COVID19: Epidemiology, evolution, and cross-disciplinary perspectives. Trends Mol Med. (2020) 26:483-95. doi: 10.1016/j.molmed.2020. 02.008
39. Plowright RK, Parrish CR, McCallum H, Hudson PJ, Ko AI, Graham AL, et al. Pathways to zoonotic spillover. Nat Rev Microbiol. (2017) 15:50210. doi: $10.1038 /$ nrmicro. 2017.45

40. Kelley LA, Mezulis S, Yates CM, Wass MK, Sternberg MJE. The Phyre2 web portal for protein modeling, prediction and analysis. Nat Protocols. (2015) 10:845-58. doi: 10.1038/nprot.2015.053

41. Guan Y, Zheng BJ, He YQ, Liu XL, Zhuang ZX, Cheung CL, et al. Isolation and characterization of viruses related to the SARS coronavirus from animals in southern China. Science. (2003) 302:276-8. doi: 10.1126/science.10 87139

42. Wang $M$, Yan $\mathrm{M}, \mathrm{Xu} \mathrm{H}$, Liang $\mathrm{W}$, Kan B, Zheng B, et al. SARS-CoV infection in a restaurant from palm civet. Emerg Infect Dis. (2005) 11:18605. doi: 10.3201/eid1112.041293

43. Song H-D, Tu C-C, Zhang G-W, Wang S-Y, Zheng K, Lei L-C, et al. Cross-host evolution of severe acute respiratory syndrome coronavirus in palm civet and human. Proc Natl Acad Sci USA. (2005) 102:24305. doi: 10.1073/pnas.0409608102

44. Liu Y, Hu G, Wang Y, Zhao X, Ji F, Ren W, et al. Functional and genetic analysis of viral receptor ACE2 orthologs reveals broad potential host range of SARS-CoV-2. BioRxiv. (2020). doi: 10.1101/2020.04.22.046565

45. Luan J, Jin $\mathrm{X}, \mathrm{Lu} \mathrm{Y}$, Zhang L. SARS-CoV-2 spike protein favors ACE2 from Bovidae and Cricetidae. J Med Virol. (2020) 92:164956. doi: $10.1002 / j m v .25817$

46. Qiu Y, Zhao YB, Wang Q, Li JY, Zhou ZJ, Liao CH, et al. Predicting the angiotensin converting enzyme 2 (ACE2) utilizing capability as the receptor of SARS-CoV-2. Microbes Infect. (2020) 22:221-5. doi: 10.1016/j.micinf.2020.03.003

47. Vincent MJ, Bergeron E, Benjannet S, Erickson BR, Rollin P, Ksiazek TG, et al. Chloroquine is a potent inhibitor of SARS coronavirus infection and spread. Virol J. (2005) 2:69. doi: 10.1186/1743-422X-2-69

48. Devaux CA, Rolain JM, Colson P, Raoult D. New insights on the antiviral effects of chloroquine against coronavirus: what to expect for COVID-19? Int J Antimicrob Agents. (2020) 55:105938. doi: 10.1016/j.ijantimicag.2020.105938

49. Beer M. COVID-19: Experimental Infection of Fruit Bats, Ferrets, Pigs, and Chicken with SARS-CoV-2 at Friedrich-Loeffler-Institut, ProMed International Society for Infectious Diseases. (2020). Available online at: https://scholar. harvard.edu/files/kleelerner/files/20200407_promed_-_coronavirus_disease_ 2019_update_88_germany_animals_research_pig_chicken_bat_ferret_pdf (accessed April 07, 2020).

50. Schlottau K, Rissmann M, Graaf A, Schön J, Sehl J, Wylezich C, et al. SARSCoV-2 in fruit bats, ferrets, pigs, and chickens: an experimental transmission study. Lancet Microbe. (2020) 1:e218-25. doi: 10.1016/S2666-5247(20)30089-6

51. Richard M, Kok A, de Meulder D, Bestebroer TM, Lamers MM, Okba NMA, et al. SARS-CoV-2 is transmitted via contact and via the air between ferrets. Nat Commun. (2020) 11:3496. doi: 10.1038/s41467-020-17367-2

52. Shi J, Wen Z, Zhong G, Yang H, Wang C, Huang B, et al. Susceptibility of ferrets, cats, dogs, and other domesticated animals to SARS-coronavirus-2. Science. (2020) 368:1016-20. doi: 10.1126/science.abb7015

53. Cantuti-Castelvetri L, Ojha R, Pedro LD, Djannatian M, Franz J, Kuivanen S, et al. Neuropilin-1 facilitates SARS-CoV-2 cell entry and infectivity. Science. (2020) 370:856-60. doi: 10.1126/science.abd2985

54. Damas J, Hughes GM, Keough KC, Painter CA, Persky NS, Corbo M, et al. Broad host range of SARS-CoV-2 predicted by comparative and structural analysis of ACE2 in vertebrates. Proc Natl Acad Sci USA. (2020). 117:2231122. doi: 10.1073/pnas.2010146117

55. Frank HK, Enard D, Boyd SD. Exceptional diversity and selection pressure on SARS-CoV and SARS-CoV-2 host receptor in bats compared to other mammals. BioRxiv. (2020). doi: 10.1101/2020.04.20.051656

56. Chu H, Chan JF-W, Yuen T-TT, Shuai H, Yuan S, Wang Y, et al. Comparative tropism, replication kinetics, and cell damage profiling of SARS-CoV-2 and SARS-CoV and implications for clinical manifestations, transmissibility and laboratory stuides of COVID-19: an observational study. Lancet Microbe. (2020) 1:e14-23. doi: 10.1016/S2666-5247(20)30004-5

57. Gretebeck LM, Subbarao K. Animal models for SARS and MERS coronaviruses. Curr Opin Virol. (2015) 13:1239. doi: 10.1016/j.coviro.2015.06.009 
58. Sutton TC, Subbarao K. Development of animal models against emerging coronaviruses: from SARS to MERS coronavirus. Virology. (2015) 479:24758. doi: 10.1016/j.virol.2015.02.030

59. Sia SF, Yan LM, Chin AWH, Fung K, Choy KT, Wong AYL, et al. Pathogenesis and transmission of SARS-CoV-2 in golden hamsters. Nature. (2020) 583:8348. doi: 10.1038/s41586-020-2342-5

60. Chan JFW, Zhang AJ, Yuan S, Poon VKM, Chan CCS, Lee ACY, et al. Simulation of the clinical and pathological manifestations of coronavirus disease 2019 (COVID-19) in golden Syrian hamster model: implications for disease pathogenesis and transmissibility. Clin Infect Dis. (2020). 71:242846. doi: 10.1093/cid.ciaa325

61. McAuliffe J, Vogel L, Roberts A, Fahle G, Fischer S, Shieh WJ, et al. Replication of SARS coronavirus administered into the respiratory tract of African Green, rhesus and cynomolgus monkeys. Virology. (2004) 330:815. doi: 10.1016/j.virol.2004.09.030

62. Rowe T, Gao G, Hogan RJ, Crytal RG, Voss TG, Grant RL, et al. Macaque model for severe acute respiratory syndrome. J Virol. (2004) 78:114014. doi: 10.1128/JVI.78.20.11401-11404.2004

63. Rockx B, Kuiken T, Herfst S, Bestebroer T, Lamers MM, Oude Munni $\mathrm{BB}$, et al. Comparative pathogenesis of COVID-19, MERS, and SARS in a nonhuman primate model. Science. (2020) 368:1012-5. doi: 10.1126/science. abb7314

64. Munster VJ, Feldmann F, Williamson BN, van Doremalen N, Pérez-Pérez L, Schulz J, et al. Respiratory disease in rhesus macaques inoculated with SARS-CoV-2. Nature. (2020) 585:268-72. doi: 10.1038/s41586-0202324-7

65. ter Meulen J, Bakker AB, van den Brink EN, Weverling GJ, Martina $\mathrm{BE}$, Haagmans BL, et al. Human monoclonal antibody as prophylaxis for SARS coronavirus infection in ferrets. Lancet. (2004) 363:213941. doi: 10.1016/S.0140-6736(04)16506-9

66. Chu YK, Ali GD, Jia F, Li Q, Kelvin D, Couch RC. The SARS-CoV ferret model in an infection-challenge study. Virology. (2008) 374:15163. doi: 10.1016/j.virol.2007.12.032

67. Glass WG, Subbarao K, Murphy B, Murphy PM. Mechanisms of host defense following severe acute respiratory syndrome-coronavirus (SARS-CoV) pulmonary infection of mice. J Immunol. (2004) 173:40309. doi: 10.4049/jimmunol.173.6.4030

68. Subbarao K, McAuliffe J, Vogel L, Fahle G, Fischer S, Tatti K, et al. Prior infection and passive transfer of neutralizing antibody prevent replication of severe acute respiratory syndrome coronavirus in the respiratory tract of mice. J Virol. (2004) 78:3572-7. doi: 10.1128/JVI.78.7.3572-3577.2004

69. Bao L, Deng W, Huang B, Gao H, Liu J, Ren L, et al. The pathogenicity of SARS-CoV-2 in hACE2 transgenic mice. Nature. (2020) 583:830-3. 2020. doi: 10.1038/s41586-020-2312-y

70. Halfmann PJ, Hatta M, Chiba S, Maemura T, Fan S, Takeda M, et al. Transmission of SARS-CoV-2 in domestic cats. New Engl J Med. (2020) 383:592-4. doi: 10.1056/NEJMc2013400

71. Segalés J, Puig M, Rodon J, Avila-Nieto C, Carrillo J, Cantero G, et al. Detection of SARS-CoV-2 in a cat owned by a COVID-19-affected patient in Spain. Proc Natl Acad Sci USA. (2020) 117:24790-3. doi: 10.1073/pnas.2010 817117

72. USDA, United States Department of Agriculture, Animal and Plant Health Inspection Service. USDA Statement on the Confirmation of COVID-19 in a Tiger in New York. (2020). Available online at: https://www.aphis.usda.gov/ aphis/newsroom/news/sa_by_date/sa-2020/ny-zoo-covid-19 (accessed April 6, 2020).

73. Oude Munnink BB, Sikkema RS, Nieuwenhuijse DF, Molenaar RJ, Munger E, Molenkamp R, et al. Transmission of SARS-CoV-2 on mink farms between humans and mink and back to humans. Science. (2020) 371:1727. doi: 10.1126/science.abe5901

74. Sun S-H, Chen Q, Gu H-J, Yang G, Wang Y-X, Huang X-Y, et al. A mouse model of SARS-CoV-2 infection and pathogenesis. Cell Host Microbe. (2020) 28:124-33. doi: 10.1016/j.chom.2020.05.020
75. Hamming I, Timens W, Bulthuis M, Lely T, Navis G, van Goor H. Tissue distribution of ACE2 protein, the functional receptor for SARS Coronavirus. J Pathol. (2004) 203:631-7. doi: 10.1002/path.1570

76. Xu H, Zhong L, Deng J, Peng J, Dan H, Zeng X, et al. High expression of ACE2 receptor of 2019-nCoV on the epithelial cells of oral mucosa. Int J Oral Sci. (2020) 12:8. doi: 10.1038/s41368-020-0074-x

77. Zhou F, Yu T, Du R, Fan G, Liu Y, Liu Z, et al. Clinical course and risk factors for mortality of adult in patients with COVID-19 in Wuhan, China: a retrospective cohort study. Lancet. (2020) 395:105462. doi: 10.1016/S0140-6736(20)30566-3

78. Zhao X, Chen D, Szabla R, Zheng M, Li G, Du P, et al. Broad and Differential Animal Angiotensin-Converting Enzyme 2 Receptor Usage by SARS-CoV. J Virol. (2020) 94:e00940-20. doi: 10.1128/JVI.00940-20

79. Brusky A. Distinct viral clades of SARS-CoV-2: implication for modeling of viral spread. J Med Virol. (2020) 92:1386-90. doi: 10.1002/jmv.25902

80. Becerra-Flores M, Cardozo T. SARS-CoV-2 viral spike G614 mutation exhibits higher case fatality rate. Int J Clin Pract. (2020) 00:e13525. doi: 10.1111/ijcp.13525

81. Korber B, Fischer WM, Gnanakaran S, Yoon H, Theiler J, Abfalterer W. STracking Changes in SARS-CoV-2 Spike: Evidence that D614G Increases Infectivity of the COVID-19 Virus. Cell. (2020) 182:81227. doi: 10.1016/j.cell.2020.06.043

82. Colson P, Levasseur A, Delerce J, Chaudet H, Bossi V, Ben Khedher M, et al. Dramatic increase in the SARS-CoV-2 mutation rate and low mortality rate during the second epidemic in summer in Marseille. IHU COVID-19. (2020). doi: 10.35088/68c3-ew82

83. Zhang L, Jackson CB, Mou H, Ojha A, Rangarajan ES, Izard T, et al. The D614G mutation in the SARS-CoV-2 spike protein reduces S1 shedding and increases infectivity. Nature Com. (2020) 11:6013. doi: 10.1038/s41467-020-19808-4

84. Watermeyer JM, Sewell BT, Scwager SL, Natesh R, Corradi HR, Acharya KR, et al. Structure of testis ACE glycosylation mutants and evidence for conserved domain movement. Biochemistry. (2006) 45:12655-63. doi: 10.1021/bi061146z

85. Gavel Y, von Heijne G. Sequence differences between glycosylated and non glycosylated Asn-X-Thr/Ser acceptor sites: implications for protein engineering. Protein Eng. (1990) 3:433-42.doi: 10.1093/protein/3.5.433

86. Devaux CA, Pinault L, Osman IO, Raoult D. Can ACE2 receptor polymorphism predicts species susceptibility to SARS-CoV-2? Res Square. (2020). doi: 10.21203/rs.3.rs-25753/v1

87. Luan J, Lu Y, Jin X, Zhang L. Spike protein recognition of mammalian ACE2 predicts the host range and an optimized ACE2 for SARS-CoV-2 infection. Biochem Biophys Res Com. (2020) 526:165-9. doi: 10.1016/j.bbrc.2020.03.047

88. Liu Z, Xiao X, Wei X, Li J, Yang J, Tan H, et al. Composition and divergence of coronavirus spike proteins and hostACE2 receptors predict potential intermediate hosts of SARS-CoV-2. J Med Virol. (2020) 92:595601. doi: 10.1002/jmv.25726

89. Mallapaty S. COVID mink analysis shows mutations not dangerous-yet. Nature. (2020) 587:340-1. doi: 10.1038/d41586-020-03218-z

90. Frutos R, Devaux CA. Mass culling of minks to protect the COVID-19 vaccines: is it rational? New Microbes New Infect. (2020) 38:100816. doi: 10.1016/j.nmni.2020.100816

Conflict of Interest: The authors declare that the research was conducted in the absence of any commercial or financial relationships that could be construed as a potential conflict of interest.

Copyright (C) 2021 Devaux, Pinault, Osman and Raoult. This is an open-access article distributed under the terms of the Creative Commons Attribution License (CC BY). The use, distribution or reproduction in other forums is permitted, provided the original author(s) and the copyright owner(s) are credited and that the original publication in this journal is cited, in accordance with accepted academic practice. No use, distribution or reproduction is permitted which does not comply with these terms. 